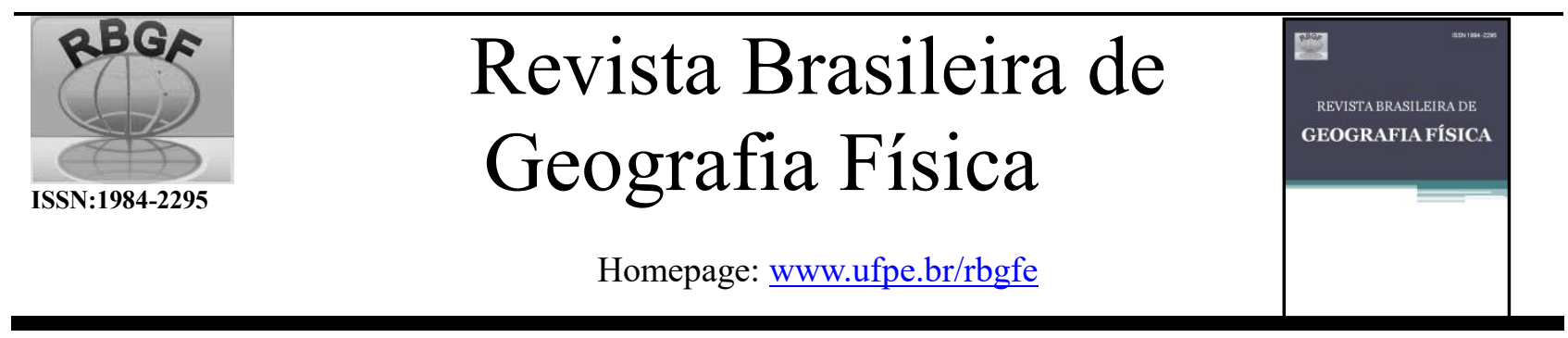

\title{
Análise da Vulnerabilidade Natural da Bacia Hidrográfica do Rio Banabuiú, com Apoio de Geotecnologia
}

\author{
Maria Maiany Paiva Lima ${ }^{1}$; Lucas da Silva ${ }^{2}$
}

\begin{abstract}
${ }^{1}$ Graduada em Engenharia Ambiental e Sanitária do Instituto Federal do Ceará, campus de Quixadá-CE, e Bolsista do Programa Institucional de Bolsas de Iniciação Científica - PIBIC. Autor correspondente: E-mail: maianypaival@gmail.com;, ${ }^{2}$ Professor do Instituto Federal do Ceará, campus de Quixadá-CE e Doutor em Desenvolvimento e Meio Ambiente pela Universidade Federal da Paraíba. E-mail: lucasilva@ifce.edu.br
\end{abstract}

Artigo recebido em 09/11/2017 e aceito em 24/07/2018

R E S U M O

A bacia hidrográfica do rio Banabuiú apresenta elevado grau de degradação ambiental, ocasionado pelo mau uso do solo, pelo baixo desenvolvimento social e econômico e principalmente pelo planejamento e gestão ineficiente de seus recursos. Em função disso, o presente trabalho teve como objetivo definir com o apoio de geotecnologias, a vulnerabilidade natural da bacia hidrográfica do referido rio, através da susceptibilidade natural dos terrenos aos processos erosivos de modo a contribuir com o desenvolvimento sustentável da bacia. Os métodos utilizados no desenvolvimento da pesquisa seguiram adaptação das metodologias proposta por Crepani (1996 e 2001), que sugerem a avaliação dos terrenos segundo a análise integrada dos aspectos do meio físico. Para tanto, foram elaborados mapas de geologia, geomorfologia, pedologia, vegetação e clima. A sobreposição dos referidos mapas em ambiente SIG gerou o mapa de vulnerabilidade natural da bacia. Constatou-se que 34,638\% da área da bacia caracteriza-se como medianamente estável/vulnerável e em 63,38\% como moderadamente estável. Também foi possível observar valores elevados de fragilidade ao longo dos rios perenizados e nas margens dos principais reservatórios, que representam riscos a bacia hidrográfica.

Palavras-chave: suscetibilidade, recursos hídricos, planejamento e gestão.

\section{Analysis of the Natural Vulnerability of the Banabuiú River Basin, with Support of Geotechnology.}

\begin{abstract}
A B S T R A C T
The watershed of the Banabuiú River presents a high degree of environmental degradation, caused by poor land use, low social and economic development and excel of the plan and inefficient management of its resources. As a result, the present work aimed to define the support of geotechnologies, a natural fragility and vulnerability of the basin of the Banabuiú river, through the natural susceptibility of the lands to erosive processes in order to contribute to the sustainable development of the basin. The methods used in the research development will follow the adaptation of the methodologies proposed by Crepani (1996 and 2001), who propose an evaluation of the lands according to an integrated analysis of the environment. For that, maps of geology, geomorphology, pedology, vegetation and climate were elaborated. The overlapping of rights in GIS paper generated the basin's natural vulnerability map. It was observed that $34.638 \%$ of the basin area is characterized as the average or vulnerable and in $63.38 \%$ as moderately stable. It is also possible to observe the high values of the reserve of the perennial rivers and in the margins of the main reservoirs, which represent risks to the river basin.
\end{abstract}

Keywords: susceptibility, water resources, planning and management.

\section{Introdução}

As bacias hidrográficas e outros ecossistemas relacionados têm desempenhado um papel significativo no abastecimento humano. No entanto, devido aos problemas crescentes de urbanização e uso da terra, além das mudanças climáticas, as bacias hidrográficas estão agora sujeitas a riscos ambientais que afetam sua gestão e sustentabilidade. Assim, é imperativo determinar as regiões vulneráveis nestas paisagens para 
identificar as áreas prioritárias que podem exigir intervenção (Tiburan Jr. et al., 2013; Tran et al., 2012).

A bacia hidrográfica do rio Banabuiú atualmente encontra-se em avançado processo de degradação ambiental, devido à presença de despejo de esgotos domésticos e efluentes industriais, à poluição dos mananciais pelos rebanhos e principalmente devido ao mau uso do solo da área de drenagem. $\mathrm{O}$ desmatamento realizado pelas atividades agropecuárias é um dos fatores que associam mais riscos à bacia, pois diminuem a proteção dos corpos hídricos, tornando-os suscetíveis ao assoreamento e à poluição por carregamento de material. E diante desse cenário de degradação ambiental é imprescindível o adequado planejamento e gestão dos recursos ambientais da bacia.

O planejamento das medidas de intervenção para a proteção das áreas de interesse à conservação da biodiversidade, em especial, ás áreas de proteção permanente do leito dos rios, deve ter como base a integridade e suscetibilidade do ambiente, que são quantificadas por meio das métricas de paisagem e resumidas em um mapa de vulnerabilidade (Caniani et al., 2016).

Gestores e formuladores de políticas públicas, muitas vezes, dependem de informações e observações para tomarem decisões, logo, as manifestações de processos sociais e ecológicos podem indicar as causas da vulnerabilidade, podendo ajudar a identificar as áreas prioritárias de ação imediata e fornecer um guia para uma investigação profunda da vulnerabilidade (Luers, 2005).

A análise da fragilidade ambiental é um instrumento que auxilia os planejadores e gestores a tomarem decisões que garantam um manejo adequado do ambiente, pois permitem avaliar suas potencialidades de forma integrada e atualmente constituem uma das principais ferramentas utilizadas pelos órgãos públicos na elaboração do planejamento territorial ambiental (Rodrigues \& Souza, 2013).

Diante do exposto, o presente trabalho tem como objetivo definir com o apoio de geotecnologias, a vulnerabilidade natural da bacia hidrográfica do rio Banabuiú, através da susceptibilidade natural dos terrenos aos processos erosivos, de modo a contribuir com o planejamento e gestão da bacia para a proteção dos recursos naturais.

\section{Material e métodos}

O método aplicado neste trabalho tem como referência a proposta apresentada por Crepani et al. (1996 e 2001), que se fundamenta no conceito de Ecodinâmica de Tricart (1977). Este conceito estabelece uma gradação entre a pedogênese, onde prevalecem os processos formadores de solos e a morfogênese, onde prevalecem os processos erosivos modificadores das formas de relevo.

O mapa de vulnerabilidade natural da Bacia Hidrográfica do Rio Banabuiú foi obtido a partir da elaboração e superposição dos mapas de geologia, geomorfologia, pedologia, vegetação e clima em ambiente SIG, no software Arcgis 10.1.

Para a elaboração do mapa temático de geologia foi utilizada a base de dados do Projeto RADAMBRASIL folhas SB.24/25 de Jaguaribe/Natal, na escala de 1:1.000.000, disponibilizados na forma digital pelo Instituto Brasileiro de Geografia e Estatística - IBGE. Já os mapas pedológicos e de vegetação foram elaborados a partir da base de dados da Fundação Cearense de Meteorologia - FUNCEME, disponíveis na escala 1:1.000.000.

O mapa de unidades geomorfológicas foi resultante da compilação dos atributos densidade de drenagem e amplitude altimétrica disponíveis no mapa de geomorfologia do Projeto RADAMBRASIL folhas SB.24/25 de Jaguaribe/Natal, na escala de 1:1.000.000, disponibilizados na forma digital pelo IBGE, juntamente com o atributo declividade que foi obtido utilizando os dados do radar SRTM (Shuttle Radar Topography Mission) disponíveis no site do United States Geological Survey - USGS https://earthexplorer.usgs.gov/ com resolução espacial de 30 metros. Foram, então, atribuídos os valores de vulnerabilidade de cada índice morfométrico conforme proposto por Crepani et al. (2001) utilizando a ferramenta Reclassify e para a determinação da vulnerabilidade com relação à geomorfologia, realizou-se a álgebra dos mapas, utilizando a ferramenta Raster Calculator, conforme apresenta a Equação 1:

$\mathrm{R}=(\mathrm{G}+\mathrm{A}+\mathrm{D}) / 3$

Onde:

$\mathrm{R}=$ Vulnerabilidade para o tema Geomorfologia;

$\mathrm{G}=$ Vulnerabilidade atribuída à densidade de drenagem;

$\mathrm{A}=$ Vulnerabilidade atribuída à Amplitude Altimétrica;

$\mathrm{D}=$ Vulnerabilidade atribuída à Declividade. 
O mapa referente ao tema clima foi adaptado para a região semiárida da sub-bacia em questão, pois a metodologia de Crepani et al. (2001) foi elaborada para a Amazônica Legal, onde os volumes pluviométricos geralmente são maiores e mais regulares, logo, a precipitação média anual foi substituída pela precipitação dos meses mais chuvosos. Segundo Andrade et al. (2006), as chuvas, no semiárido brasileiro, apresentam uma distribuição unimodal com $80 \%$ do total concentrado nos meses de fevereiro a maio.

O mapa foi, portanto, elaborado a partir das médias de precipitação dos meses mais chuvosos registradas pela FUNCEME, em 12 postos pluviométricos situados ao longo da Bacia, num intervalo de dez anos. Através da razão entre a precipitação média mensal e duração do período chuvoso, obteve-se os valores de intensidade pluviométrica, de acordo com a Equação 2:

\section{$\mathrm{IP}=\mathrm{PMM} / \mathrm{DPC}$}

Onde:

IP = Intensidade Pluviométrica;

$\mathrm{PMM}=$ Precipitação Média mensal;

$\mathrm{DPC}=$ Duração do Período Chuvoso.

Os dados pluviométricos associados ao posicionamento geográfico dos postos pluviométricos foram interpolados no software Arcgis 10.1 e a partir do resultado foram geradas as isoietas relativas à intensidade pluviométrica.

Os mapas temáticos de geologia, vegetação e pedologia confeccionados encontravam-se em formato Shapfile e foram transformados para o formato Raster. Após a conversão foram atribuídos pesos de vulnerabilidade natural com base nos valores propostos por Crepani et al. (2001) variando de $1 \mathrm{a}$ 3 , sendo valores próximos de 1 para atributos considerados estáveis, onde predomina a pedogênese, ao redor de 2 para os intermediários e próximos de 3 para os instáveis, onde predomina a morfogênese. Esses valores de vulnerabilidade foram atribuídos para cada atributo dos temas geologia, geomorfologia, pedologia, vegetação e clima por meio da utilização da ferramenta Reclassify.

O mapa de vulnerabilidade natural foi obtido após a álgebra de mapas das grades de vulnerabilidade para os temas citados anteriormente. A álgebra consistiu na média aritmética dos cinco mapas elaborados anteriormente através da ferramenta Math, conforme apresenta a Equação 3.

$\mathrm{V}=(\mathrm{G}+\mathrm{D}+\mathrm{S}+\mathrm{Vg}+\mathrm{C}) / 5$

Onde:

$\mathrm{V}=$ Vulnerabilidade;

$\mathrm{G}=$ Vulnerabilidade para o tema Geologia;

$\mathrm{D}=$ Vulnerabilidade para o tema Declividade;

$\mathrm{S}=$ Vulnerabilidade para o tema Solo;

$\mathrm{Vg}=$ Vulnerabilidade para o tema Vegetação e $\mathrm{C}=$ Vulnerabilidade para o tema Clima.

\section{Resultados e discussão \\ Geologia}

Para o cálculo da vulnerabilidade natural com base no fator geologia foram considerados os aspectos relativos às características litológicas, mais precisamente ao grau de coesão das rochas. Segundo Crepani et al. (2001), esta característica é a mais influente na determinação da vulnerabilidade do fator geologia, pois é sabido que as rochas mais coesas são formadas por minerais que apresentam ligações mais intensas e consequentemente mais difíceis de serem rompidas.

Através das informações obtidas em Brasil (1981), foram determinadas as unidades geológicas presentes na Bacia do Rio Banabuiú (Figura 1), bem como suas respectivas litologias, e com base nas mesmas foram definidos os valores de vulnerabilidade, segundo a classificação proposta por Crepani et al. (2001), como mostra a Tabela 1. 


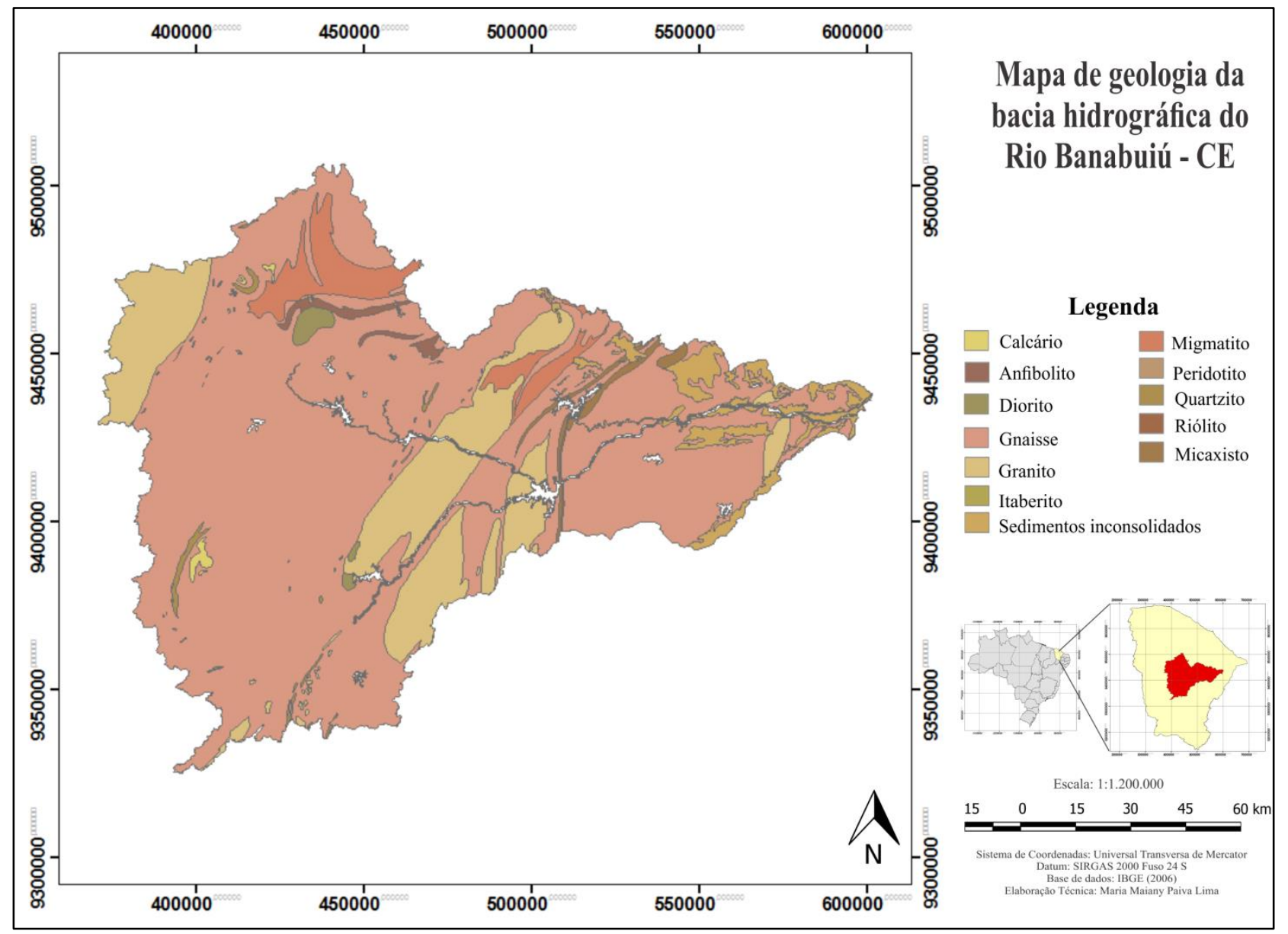

Figura 1: Mapa de Geologia da Bacia Hidrográfica do Rio Banabuiú.

Tabela 1: Valores de vulnerabilidade natural da estrutura geológica da Bacia Hidrográfica do Rio Banabuiú.

\begin{tabular}{lll}
\hline Litologia & Área (\%) & Vulnerabilidade \\
\hline Sedimentos inconsolidados & 3,662 & 3,0 \\
\hline Calcários & 0,299 & 2,9 \\
\hline Micaxistos & 0,887 & 1,9 \\
\hline Anfibolitos & 0,710 & 1,8 \\
\hline Peridotito & 0,015 & 1,6 \\
\hline Dioritos & 0,585 & 1,5 \\
\hline Itabiritos & 0,001 & 1,3 \\
\hline Gnaisses & 72,316 & 1,3 \\
\hline Migmatitos & 4,242 & 1,3 \\
\hline Riólitos & 0,710 & 1,1 \\
\hline Granito & 15,978 & 1,1 \\
\hline Quartzitos & 0,533 & 1,0 \\
\hline
\end{tabular}

Fonte: Adaptado de Crepani et al., 2001.

Em geral, os setores formados por rochas magmáticas ou metamórficas apresentam, do ponto de vista geológico, maior resistência aos processos de intemperismo devido à maior coesão dos minerais constituintes. Em função disto, a vulnerabilidade varia de estável (valores próximos a 1,0$)$ quando formado por rochas magmáticas, a medianamente estável (valores próximos de 2,0) quando formado por rochas metamórficas. Já os setores de maior vulnerabilidade à erosão estão associados às litologias mais tenras, representadas por rochas sedimentares com valor de vulnerabilidade próximos de 3. (Crepani et al. 2001). Entretanto, cada tipo de litologia apresenta 
peculiaridades que podem agregar maior ou menor vulnerabilidade, independente de sua origem, como por exemplo, o quartzito, que é uma classe de rocha metamórfica dura e compacta, devido a isso apresenta menor vulnerabilidade, enquanto o diorito, apesar de ser uma rocha magmática, apresenta maior vulnerabilidade em virtude do déficit de sílica em sua composição.

A distribuição das litologias na área de estudo permite observar que em aproximadamente $72 \%$ da bacia predominam os gnaisses, caracterizados como rochas metamórficas. Essas rochas possuem alta resistência ao intemperismo e são geralmente observadas em regiões de solo pedregoso ou onde há afloramento de granito (Gomes, 2005).

Segundo Mota (2011), as áreas que têm em sua composição rochas sedimentares apresentam maior instabilidade e localizam-se principalmente ao longo dos leitos dos rios, pois essas são áreas de acumulação de material transportado principalmente pela água. Considerando que o fluxo dos principais rios da bacia do Banabuiú acontece no sentido oeste-leste, pode-se observar no mapa de geologia (Figura 1) que as litologias sedimentares (calcário e sedimentos inconsolidados) predominam no exutório da bacia, onde os principais cursos d'água convergem, confirmando assim o exposto por Mota (2011) e Crepani et al. (2001).

\section{Geomorfologia}

A análise da vulnerabilidade do atributo geomorfologia com base na metodologia de Crepani et al. (2001) é realizada a partir da média dos atributos morfométricos de densidade de drenagem, amplitude altimétrica e declividade.
A densidade de drenagem é expressa pela relação do comprimento total dos cursos d'água da bacia e sua área total (Swami e Mattos, 1975). Quanto menor for a densidade de drenagem (ou menor for a intensidade de dissecação) menores são os valores atribuídos às unidades de paisagem natural na escala de vulnerabilidade, ou seja, valores mais próximos à estabilidade (próximos a $1,0)$, da mesma forma as unidades de paisagem natural que apresentem maiores densidades de drenagem (ou maiores intensidades de dissecação) recebem valores da escala de vulnerabilidade mais próximos de 3,0 (próximos da vulnerabilidade) (Crepani et al., 2001).

O aprofundamento da dissecação é determinado pela amplitude altimétrica e diretamente proporcional à energia potencial disponível para o "runoff", ou escoamento artificial, pois as águas de precipitação que caem sobre os pontos mais altos do terreno adquirirão maior energia cinética no seu percurso em direção às partes mais baixas e, consequentemente, apresentarão maior capacidade de morfogênese (Crepani et al., 2001). Quanto maior for a amplitude altimétrica, maior será o valor na escala de vulnerabilidade (próximo de 3,0), em contrapartida, aos menores valores de amplitude altimétrica estão associados os menores valores da escala de vulnerabilidade (próximos de 1,0), que traduzem situações de maior estabilidade das unidades de paisagem natural, onde prevalecem os processos pedogenéticos.

A partir das informações obtidas na base de dados do projeto RADAMBRASIL (Brasil,1981), foram confeccionados os mapa de densidade de drenagem e amplitude altimétrica (Figuras 2 e 3) e determinadas as vulnerabilidades para os referidos temas, conforme as Tabelas 2 e 3. 
Revista Brasileira de Geografia Física v.11, n.04 (2018) 1442-1457.

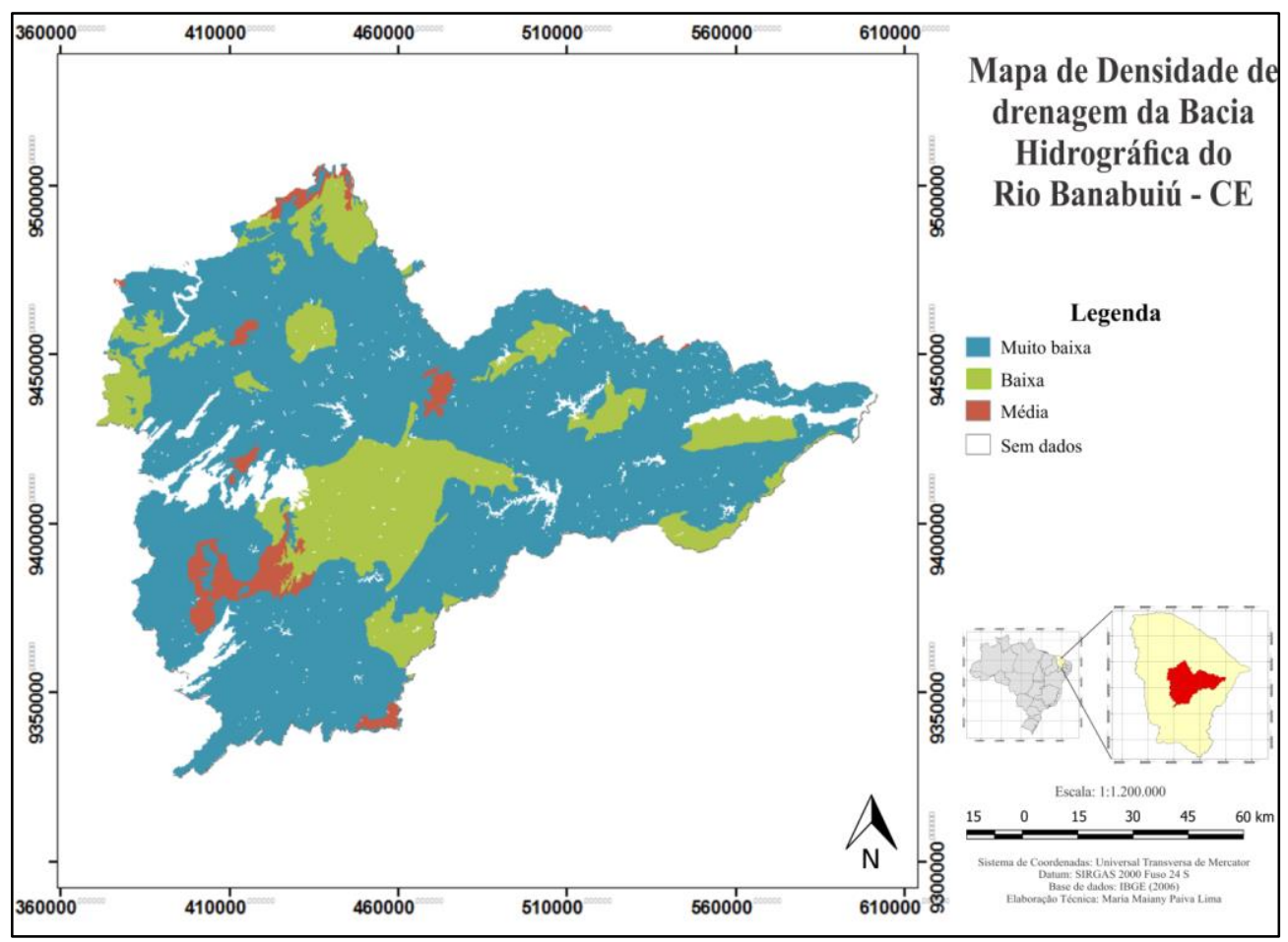

Figura 2: Mapa de Densidade de Drenagem da Bacia Hidrográfica do Rio Banabuiú.

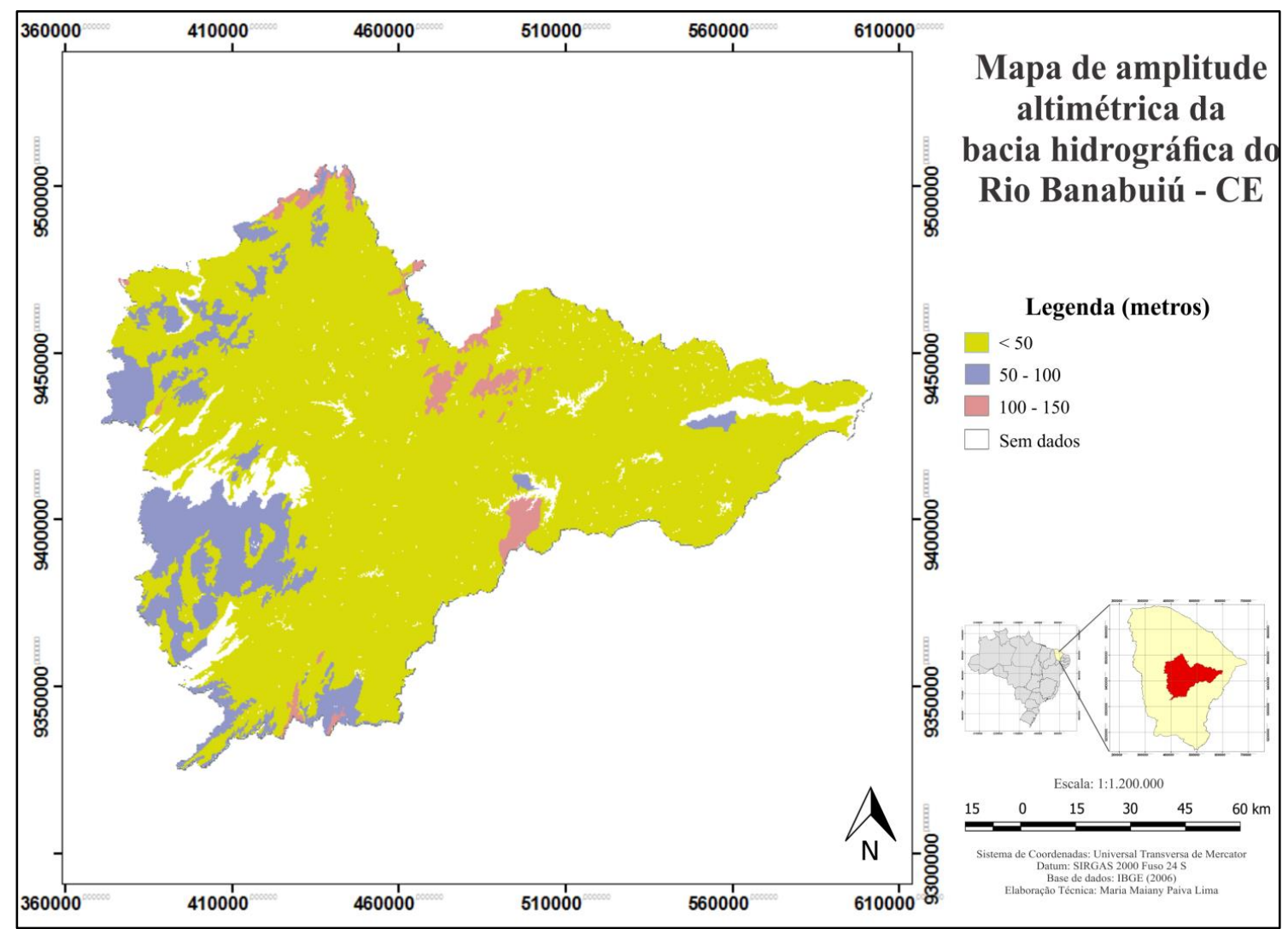

Figura 3: Mapa de Amplitude Altimétrica da Bacia Hidrográfica do Rio Banabuiú 
Revista Brasileira de Geografia Física v.11, n.04 (2018) 1442-1457.

Tabela 2: Valores de vulnerabilidade natural da densidade de drenagem da Bacia Hidrográfica do Rio Banabuiú.

\begin{tabular}{lll}
\hline Densidade de drenagem & Área (\%) & Vulnerabilidade \\
\hline Muito baixa & 19,09 & 1 \\
\hline Baixa & 71,53 & 1,5 \\
\hline Media & 3,5 & 2 \\
\hline Sem dados & 5,88 & - \\
\hline
\end{tabular}

Fonte: Adaptado de Crepani et al., 2001; Adaptado de Brasil (1981).

Tabela 3: Valores de vulnerabilidade natural da amplitude altimétrica da Bacia Hidrográfica do Rio Banabuiú.

\begin{tabular}{lll}
\hline Amplitude altimétrica (m) & Área (\%) & Vulnerabilidade \\
\hline$<50$ & 79,07 & 1,2 \\
\hline $50-100$ & 12,40 & 1,7 \\
\hline $100-150$ & 2,65 & 2,2 \\
\hline Sem dados & 5,88 & - \\
\hline
\end{tabular}

Fonte: Adaptado de Crepani et al., 2001; Adaptado de Brasil (1981).

Segundo Crepani et al. (2001), o atributo morfométrico da declividade refere-se à inclinação do relevo em relação ao horizonte e está relacionada à velocidade do escoamento superficial "runoff". Quando maior a declividade maior será a velocidade das massas d'água e sua capacidade de transporte responsável pela erosão, onde prevalecem os processos de morfogênese com valores de vulnerabilidade altos (próximos de 3 ) e da mesma forma, as unidade de paisagem natural que apresentam menor declividade, caracterizamse como estáveis, apresentando valores próximos a 1 , conforme apresentado no mapa de declividade elaborado a partir das imagens SRTM (Figura 4) e na Tabela 4. 


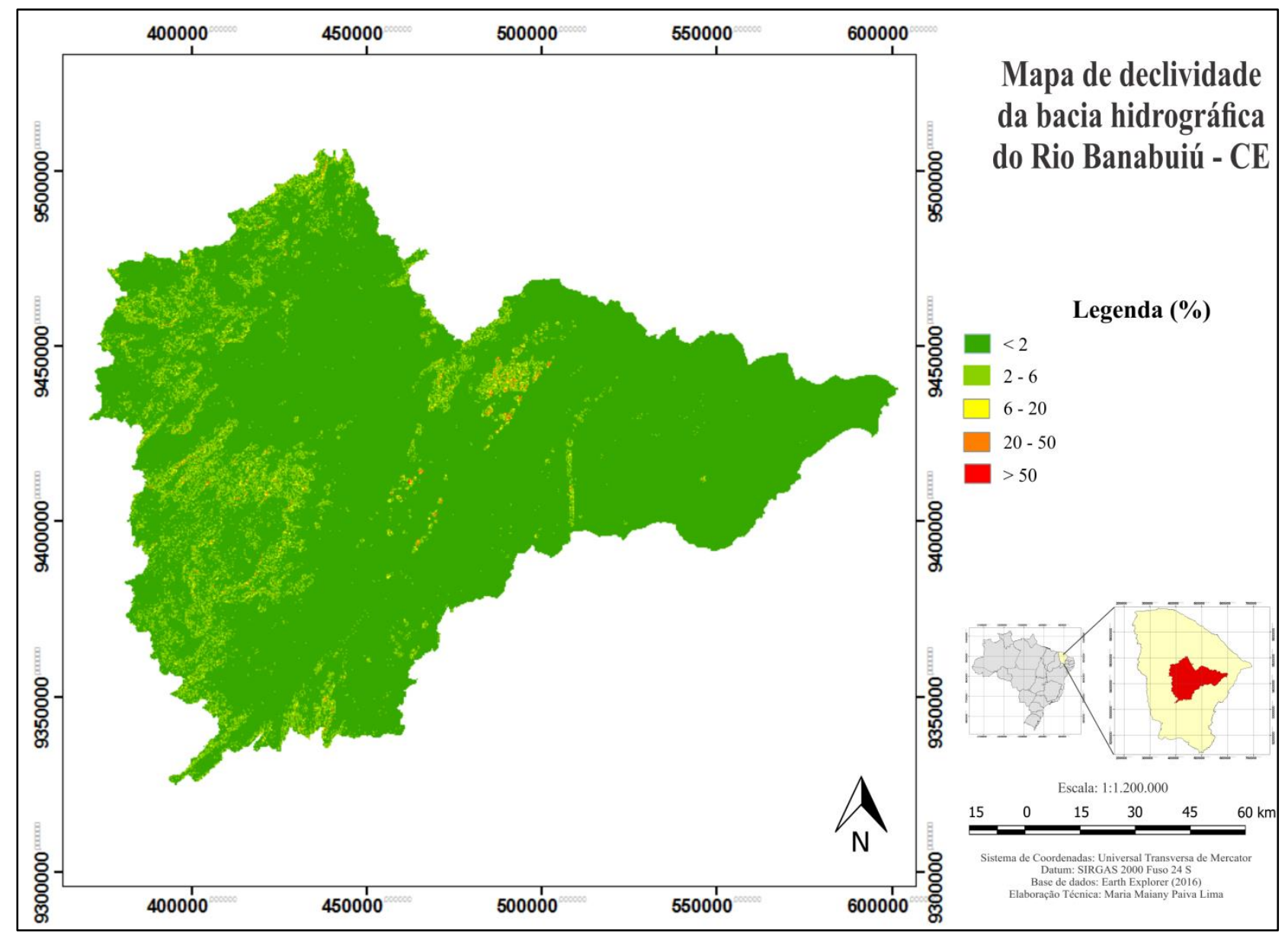

Figura 4: Mapa de Declividade da Bacia Hidrográfica do Rio Banabuiú.

Tabela 4: Valores de vulnerabilidade natural da declividade da Bacia Hidrográfica do Rio Banabuiú.

\begin{tabular}{lll}
\hline Declividade (\%) & Área & Vulnerabilidade \\
\hline$<2$ & 90,61 & 1 \\
\hline $2-6$ & 8,65 & 1,5 \\
\hline $6-20$ & 0,74 & 2 \\
\hline $20-50$ & 0,01 & 1,5 \\
\hline$>50$ & 0 & 3 \\
\hline
\end{tabular}

Fonte: Crepani et al. (2001).

A vulnerabilidade com relação à geomorfologia (Figura 5) foi definida a partir da média aritmética das vulnerabilidades atribuídas aos índices morfométricos, conforme a fórmula proposta por Crepani et al. (2001), e sua distribuição percentual na área de estudo é apresentada na Tabela 5. 


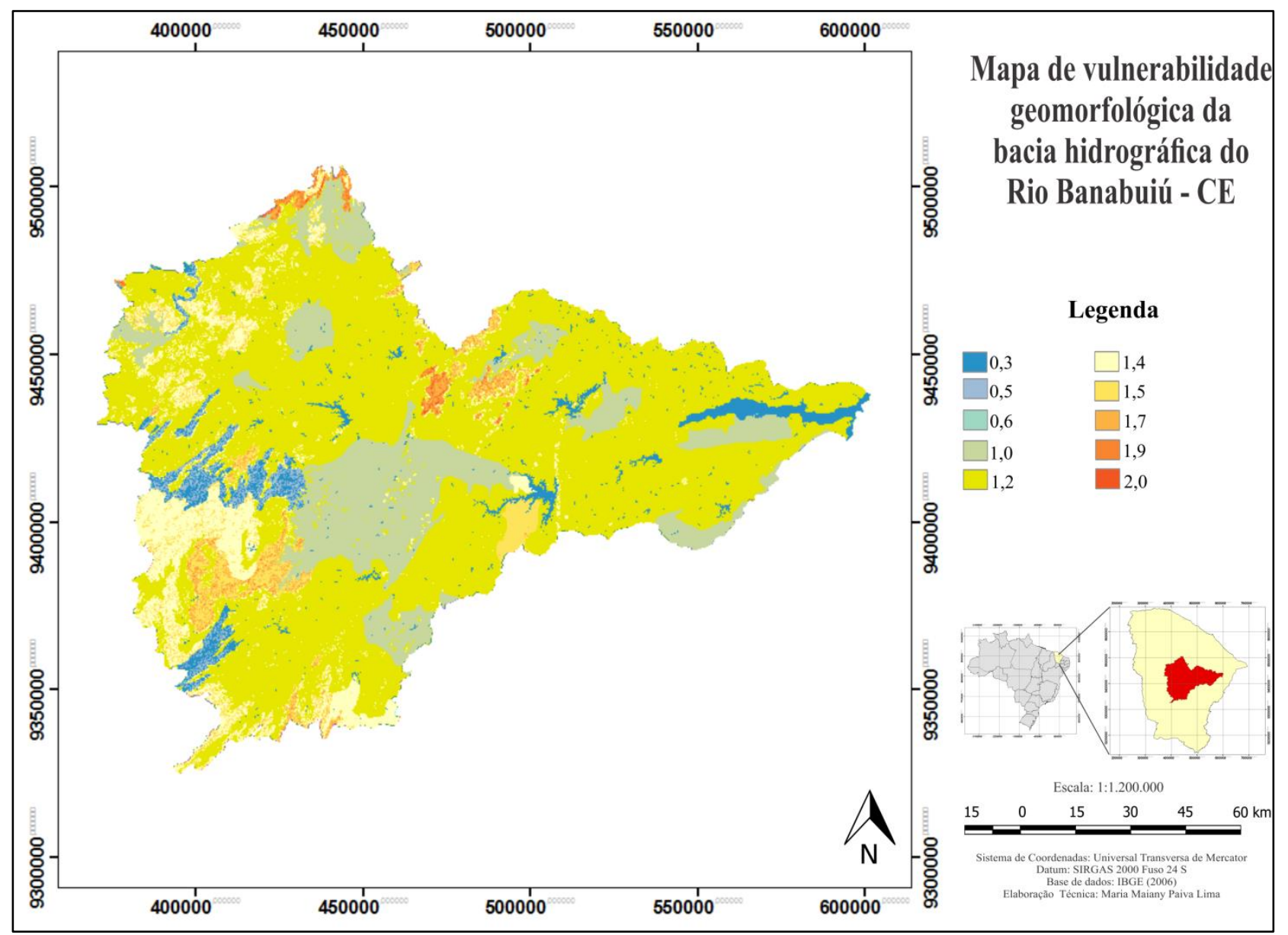

Figura 5: Mapa de Vulnerabilidade Geomorfológica da Bacia Hidrográfica do Rio Banabuiú.

Tabela 5: Distribuição dos valores de vulnerabilidade geomorfológica da Bacia Hidrográfica do Rio Banabuiú.

\begin{tabular}{|c|c|c|c|}
\hline Vulnerabilidade & Área (\%) & $\begin{array}{l}\text { Grau de } \\
\text { vulnerabilidade }\end{array}$ & Área (\%) \\
\hline 0,3 & 4,24 & \multirow[t]{5}{*}{ Estável } & \multirow[t]{5}{*}{83,85} \\
\hline 0,5 & 1,49 & & \\
\hline 0,6 & 0,16 & & \\
\hline 1,0 & 16,08 & & \\
\hline 1,2 & 61,88 & & \\
\hline 1,4 & 8,95 & \multirow[t]{3}{*}{ Moderadamente estável } & \multirow[t]{3}{*}{15,52} \\
\hline 1,5 & 4,69 & & \\
\hline 1,7 & 1,88 & & \\
\hline 1,9 & 0,55 & \multirow{2}{*}{$\begin{array}{l}\text { Moderadamente } \\
\text { estável/vulnerável }\end{array}$} & \multirow[t]{2}{*}{0,62} \\
\hline 2,0 & 0,07 & & \\
\hline
\end{tabular}

A partir da análise do mapa de vulnerabilidade geomorfológica pode-se observar que os maiores valores de vulnerabilidade foram encontrados nas superfícies mais aguçadas do relevo, principalmente nos setores de inselbergs, entre os municípios de Quixadá e Quixeramobim. Já no curso superior da bacia, onde predominam as superfícies serranas, foram observadas unidades de paisagem moderadamente estáveis. Contudo, a maior parte da bacia caracteriza-se como estável, principalmente no domínio da depressão sertaneja que, segundo o Serviço geológico do Brasil CPRM (2003), é caracterizada pela ocorrência de pediplanos dissecados pela rede de drenagem, com formação de planícies alveolares.

\section{Pedologia}


O mapeamento da vulnerabilidade dos solos é fundamental ao entendimento do seu potencial de erodibilidade de acordo com suas características. A perda de solo por erosão é atualmente uma das principais causas da degradação do solo e da água com impactos negativos sobre o ecossistema em geral (Lopes 2011; Panagos et al., 2015).
A distribuição das tipologias pode ser observada no mapa pedológico (Figura 6) e a definição dos grupos de solo quanto à vulnerabilidade é feita conforme a Tabela 6. Os valores contidos na tabela apresentam um indicativo da fragilidade da Bacia do Rio Banabuiú, onde quase metade da área $(45,7 \%)$ é ocupada por solos categorizados como vulneráveis.

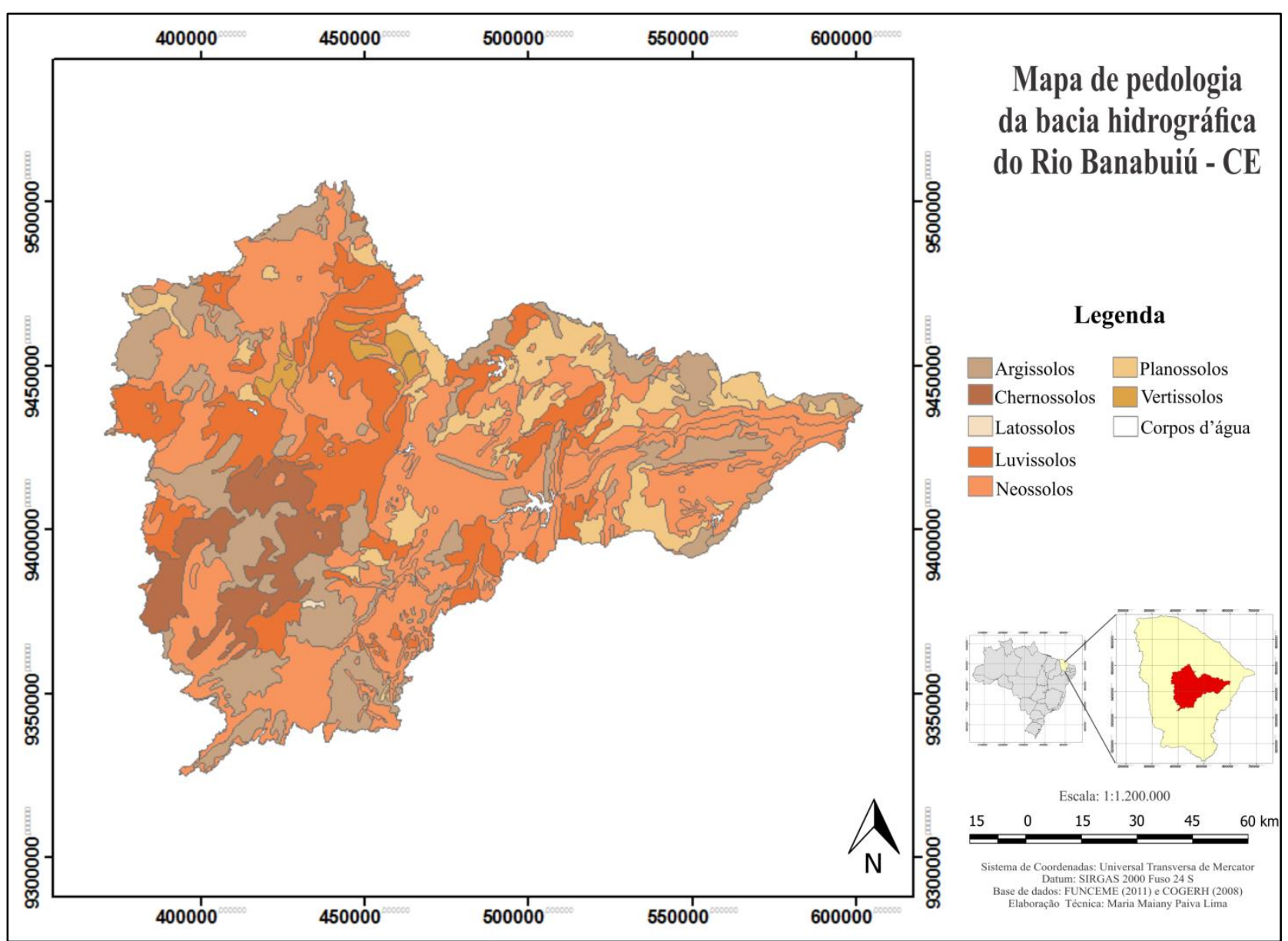

Figura 6: Mapa de Pedologia da Bacia Hidrográfica do Rio Banabuiú.

Tabela 6: Valores de vulnerabilidade natural da pedologia da Bacia Hidrográfica do Rio Banabuiú.

\begin{tabular}{lll}
\hline Classe de solo & Área (\%) & Vulnerabilidade \\
\hline Latossolos & 0,06 & 1 \\
\hline Argissolos & 19,37 & 2 \\
\hline Luvissolos & 17,85 & 2 \\
\hline Chernossolos & 7,07 & 2 \\
\hline Planossolos & 9,9 & 2 \\
\hline Neossolos & 44,41 & 3 \\
\hline Vertissolos & 1,33 & 3 \\
\hline
\end{tabular}

Fonte: Adaptado de Crepani et al., 2001.

Segundo Crepani et al. (2001), nos solos caracterizados como vulneráveis o horizonte A está assentado diretamente sobre o horizonte $\mathrm{C}$ ou então assentado diretamente sobre a rocha mãe (não possuem o horizonte B). São considerados como solos jovens, em fase inicial de formação porque estão ainda se desenvolvendo a partir dos materiais de origem recentemente depositados, ou então 
porque estão situados em lugares de alta declividade, nos quais a velocidade da erosão é igual ou maior que a velocidade de transformação da rocha em solo com destaque para os Neossolos que ocupam 44,41\% da área da bacia estudada.

Pouco mais da metade dos solos da bacia $(54,19 \%)$ são enquadrados como solos moderadamente vulneráveis, que caracterizam as unidades de paisagem natural intermediárias. Os mais representativos dessa classe na bacia são os argissolos e os luvissolos que são menos profundos e menos intemperizados que os solos considerados de unidades de paisagem natural estáveis, como os latossolos, que representam menos de $1 \%$ das classes de solos presentes na bacia.

\section{Vegetação}

O parâmetro considerado para determinar a vulnerabilidade do tema vegetação é a densidade de cobertura vegetal, pois se caracteriza como um fator de proteção da unidade contra os processos morfogenéticos. Crepani et al. (2001) propõe uma escala de vulnerabilidade para o tema na qual a menor vulnerabilidade (valores próximos a 1,0) é atribuída às coberturas vegetais mais densas, em virtude da maior proteção que a vegetação oferece ao solo. Nas áreas de média densidade de cobertura vegetal os valores ficam próximos de 2,0 e as áreas com maior valor de vulnerabilidade (próximo de 3) apresentam baixa densidade de cobertura vegetal.

As classes de vegetação da Bacia Hidrográfica do Rio Banabuiú estão apresentadas na Figura 7 e os valores de vulnerabilidade atribuídos para cada classe encontrada é obsevado na Tabela 7.

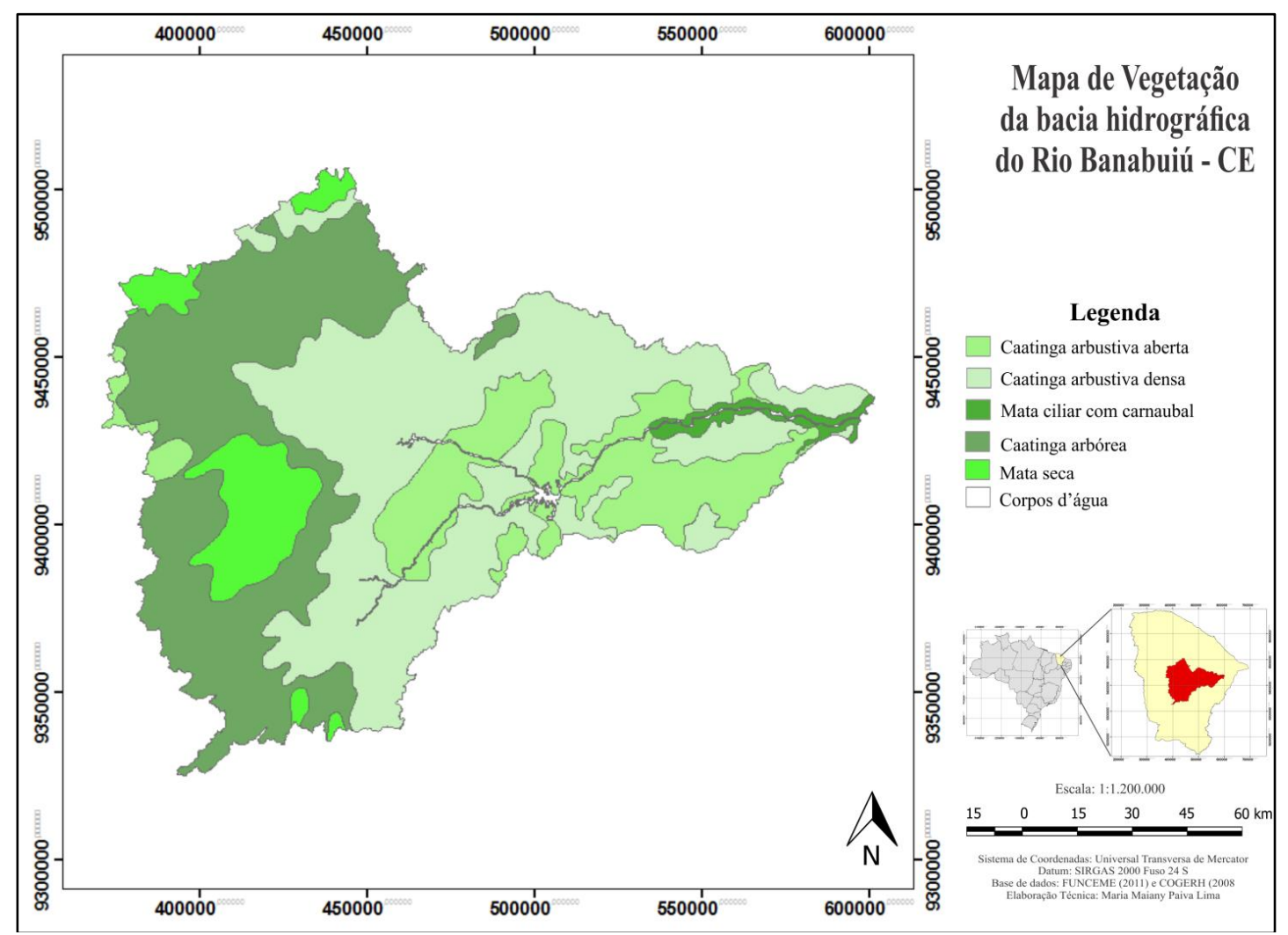

Figura 7: Mapa de Vegetação da Bacia Hidrográfica do Rio Banabuiú

Tabela 7: Valores de vulnerabilidade natural da vegetação da Bacia Hidrográfica do Rio Banabuiú.

\begin{tabular}{lll}
\hline Classe de solo & Área $\mathbf{~ \% )}$ & Vulnerabilidade \\
\hline Mata seca & 7,96 & 1,7 \\
\hline Caatinga arbórea & 32,30 & 2,9 \\
\hline Mata ciliar com carnaubal & 1,59 & 2 \\
\hline Caatinga arbustiva densa & 41,22 & 2,6 \\
\hline Caatinga arbustiva aberta & 16,93 & 2,8 \\
\hline
\end{tabular}

Fonte: Adaptado de Crepani et al., 2001; Adaptado de Fernandes, 1998. 
A classificação adotada no mapa foi proposta por Fernandes (1998) que leva em consideração principalmente a fisionomia do ambiente. A caatinga arbórea que representa 32,3\% da vegetação é caracterizada pelo autor como um tipo florestal e confere estabilidade às unidades de paisagem natural, geralmente se encontram mais protegidas, mas essa vegetação tem diminuído devido à degradação antrópica.

A caatinga arbustiva representa o padrão mais generalizado, sendo também conhecida como caatinga baixa. Ela é geralmente resultado da ação predatória do homem e pode apresentar um padrão mais denso, que é o mais comum, e outro aberto, sendo o primeiro menos vulnerável que o último (Fernandes, 2006).

\section{Clima}

O fator climático para considerar a vulnerabilidade natural é representado pelo potencial da chuva remover o solo pela erosão hídrica, chamado de intensidade pluviométrica. $\mathrm{O}$ impacto direto das gotas e o escoamento superficial do excesso de água da chuva ("runoff" ou enxurrada) são os agentes ativos da erosão hídrica, o solo é o agente passivo (Crepani et al., 2001).

A intensidade pluviométrica representa uma relação entre o quanto choveu e quando choveu. Ela resulta na quantidade de energia potencial disponível para transformar-se em energia cinética e sua maior importância é facilmente verificada quando se observa que uma elevada pluviosidade anual bem distribuída tem menor potencial erosivo que uma chuva de mesmo volume em um curto período de tempo (Crepani et al., 2001).

O clima da área de estudo é Tropical Quente Semiárido e caracteriza-se pela sazonalidade das chuvas, portanto o parâmetro de intensidade pluviométrica torna o principal responsável pela denudação dessa região. A distribuição da intensidade pluviométrica encontra-se na Figura 8 e os valores propostos por Crepani et al., (2001) para a vulnerabilidade decorrente da intensidade pluviométrica estão apresentados na Tabela 8 .

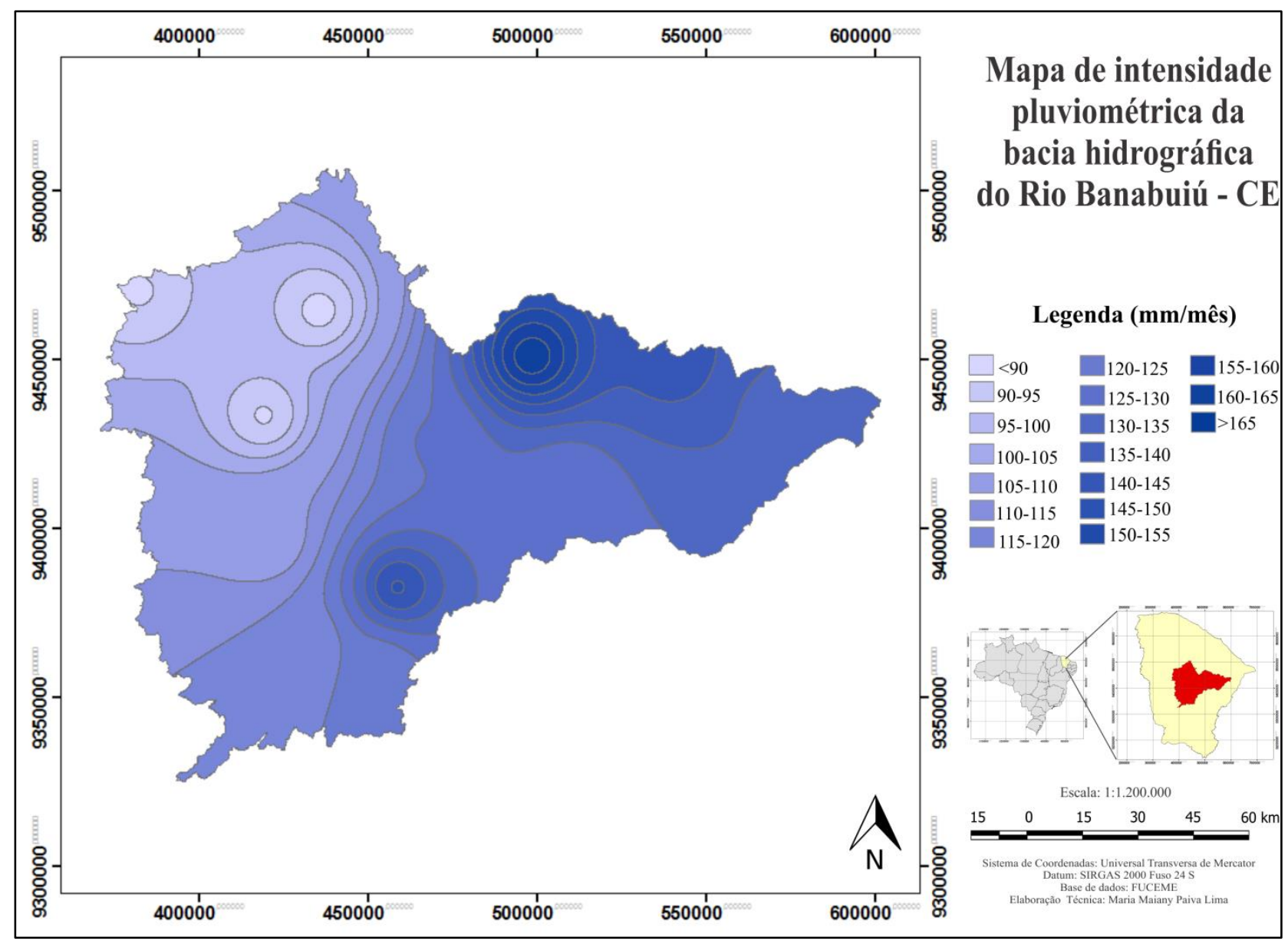

Figura 8: Mapa de Intensidade Pluviométrica da Bacia Hidrográfica do Rio Banabuiú. 
Revista Brasileira de Geografia Física v.11, n.04 (2018) 1442-1457.

Tabela 8: Valores de vulnerabilidade natural da intensidade pluviométrica da Bacia Hidrográfica do Rio Banabuiú.

\begin{tabular}{lll}
\hline Intensidade pluviométrica $\mathbf{( m m} / \mathbf{m e ̂ s})$ & Área $\mathbf{( \% )}$ & Vulnerabilidade \\
\hline $90-95$ & 0,79 & 1,2 \\
\hline $95-100$ & 4,62 & 1,2 \\
\hline $100-105$ & 10,27 & 1,3 \\
\hline $105-110$ & 6,32 & 1,3 \\
\hline $110-115$ & 12,48 & 1,3 \\
\hline $115-120$ & 6,69 & 1,3 \\
\hline $120-125$ & 10,11 & 1,3 \\
\hline $125-130$ & 6,83 & 1,4 \\
\hline $130-135$ & 13,70 & 1,4 \\
\hline $135-140$ & 13,86 & 1,4 \\
\hline $140-145$ & 5,61 & 1,4 \\
\hline $145-150$ & 4,50 & 1,4 \\
\hline $150-155$ & 1,65 & 1,5 \\
\hline $155-160$ & 1,23 & 1,5 \\
\hline $160-165$ & 0,89 & 1,5
\end{tabular}

Fonte: Adaptado de Crepani et al., 2001.

Vulnerabilidade natural da Bacia Hidrográfica do Rio Banabuiú

A Figura 9 apresenta o mapa de vulnerabilidade ambiental da bacia hidrográfica do
Rio Banabuiú, resultado da média aritmética dos fatores Geologia, Geomorfologia, Solos, Vegetação e Clima anteriormente descritos, e a Tabela 9 apresenta as áreas ocupadas pelas classes e pelos diferentes graus de vulnerabilidade das unidades de paisagem. 


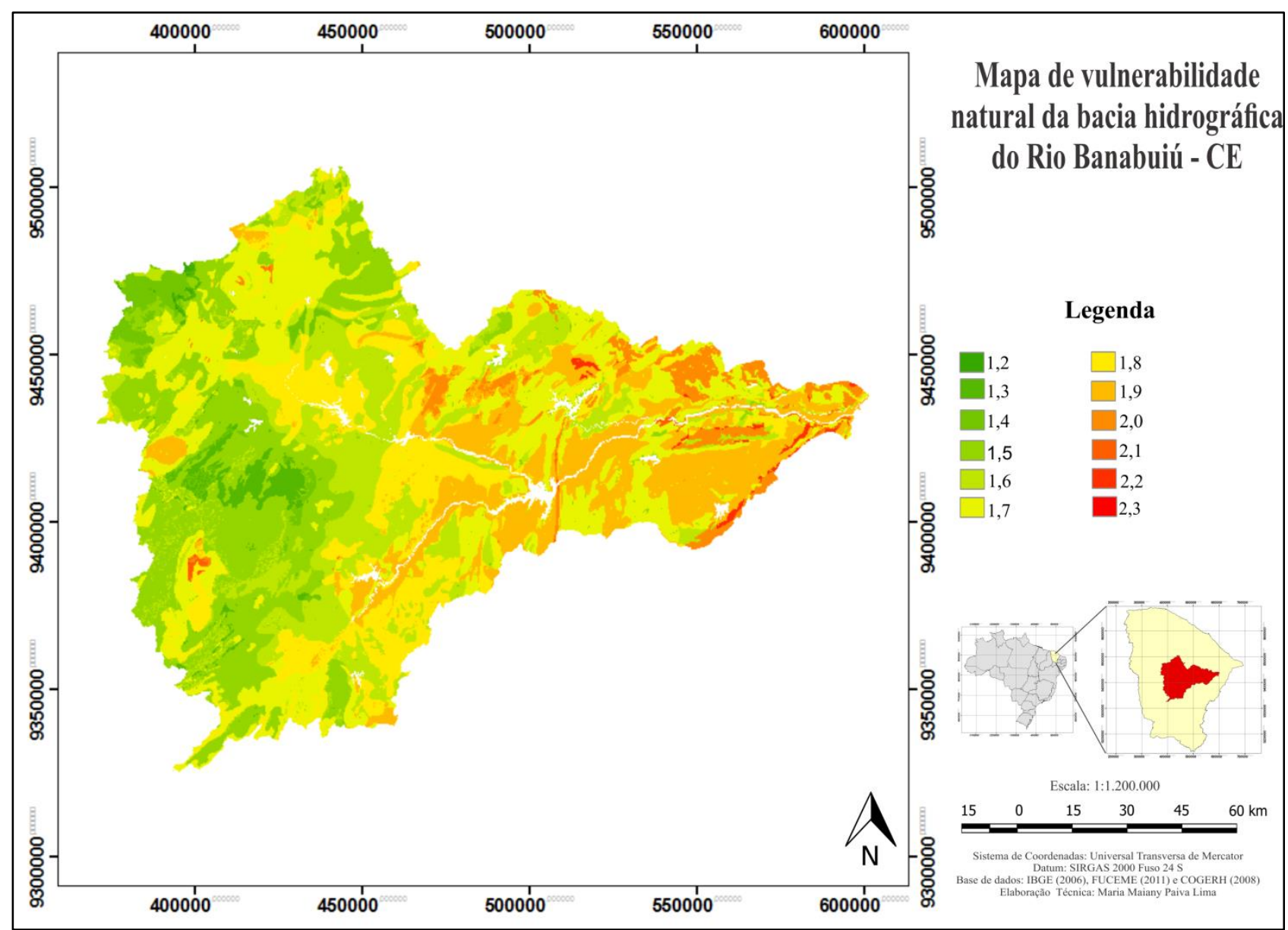

Figura 9: Vulnerabilidade natural da Bacia Hidrográfica do Rio Banabuiú.

Tabela 9: Valores de vulnerabilidade natural da Bacia Hidrográfica do Rio Banabuiú.

\begin{tabular}{|c|c|c|c|}
\hline Vulnerabilidade & Área (\%) & Grau de vulnerabilidade & Área (\%) \\
\hline 1,2 & 0,078 & \multirow{2}{*}{ Estável } & \multirow[t]{2}{*}{1,982} \\
\hline 1,3 & 1,903 & & \\
\hline 1,4 & 2,293 & \multirow[t]{4}{*}{ Moderadamente estável } & \multirow[t]{4}{*}{63,380} \\
\hline 1,5 & 20,23 & & \\
\hline 1,6 & 17,04 & & \\
\hline 1,7 & 23,81 & & \\
\hline 1,8 & 14,99 & \multirow{5}{*}{$\begin{array}{l}\text { Medianamente } \\
\text { estável/vulnerável }\end{array}$} & \multirow[t]{5}{*}{34,638} \\
\hline 1,9 & 15,31 & & \\
\hline 2,0 & 3,674 & & \\
\hline 2,1 & 0,263 & & \\
\hline 2,2 & 0,396 & & \\
\hline 2,3 & 0,001 & $\begin{array}{l}\text { Moderadamente } \\
\text { vulnerável }\end{array}$ & 0,001 \\
\hline
\end{tabular}

A análise dos dados permite inferir que a classe considerada moderadamente estável predomina em $63,38 \%$ da área da bacia, conforme é mostrado na Tabela 9. A classe medianamente estável/vulnerável representa $34,638 \%$ da região estudada. Pode-se dizer que quase totalidade da área (mais de 98\%) pertence às classes moderadamente estável e medianamente estável/vulnerável.

Os baixos valores de vulnerabilidade estão associados principalmente à composição geológica da bacia que corresponde principalmente a rochas resistentes ao intemperismo associadas com as extensas áreas aplainadas e a baixa densidade de drenagem. O estudo de Aquino et al. (2016) 
também comprovou a influência das áreas aplainadas predominantes na região para a determinação da vulnerabilidade e Mota \& Valladares (2011) em seu trabalho sobre a bacia do Acaraú, fronteiriça à bacia de estudo, também destacaram a influência da predominância de rochas coesas na vulnerabilidade natural.

Ao observar a distribuição ao longo da bacia percebe-se forte influência da vegetação, pois as superfícies que predominam vegetação mais rala (menos densa) estão associadas a valores mais altos de vulnerabilidade, apesar dos demais fatores considerados.

Ao longo dos rios perenizados e nas margens dos principais reservatórios da bacia observam-se valores elevados de vulnerabilidade que representam riscos à bacia, visto que esses rios e reservatórios estão mais suscetíveis ao assoreamento e à poluição. Considerando a importância dos mesmos para o abastecimento da região, torna-se imprescindível a adoção de medidas que visem sua proteção, como o controle do uso do solo nas suas margens e a manutenção da vegetação natural, principalmente por se tratar de uma região semiárida com escassez hídrica.

A gestão eficiente dos recursos hídricos é uma política fundamental às zonas áridas, haja vista que promove uma melhor compreensão dos integrados e inter-relacionados sistemas ambientais e socioecológicos (Hu 2014). Segundo Gomes et al. (2005), a aplicação da metodologia de vulnerabilidade natural fornece uma visão geral e sistêmica de como o ambiente semiárido se comporta.

\section{Conclusões}

Através do mapeamento realizado, foi possível verificar que o grau de vulnerabilidade natural à erosão da bacia hidrográfica do rio Banabuiú não se mostrou expressivo, ocorrendo o predomínio da classe medianamente estável/vulnerável e moderadamente estável em mais de $98 \%$ da área. O mapa de vulnerabilidade também permitiu observar que os recurso hídricos da bacia estão mais suscetíveis a riscos ambientais.

A metodologia de Crepani et al. (2001) modificada permitiu o conhecimento da morfodinâmica da bacia hidrográfica do rio Banabuiú e sua classificação em unidades de paisagem de acordo com o grau de vulnerabilidade natural, fornecendo subsídios ao planejamento e ordenamento territorial da área de estudo.

\section{Agradecimentos}

Ao Instituto Federal de Educação, Ciência e Tecnologia do Ceará.

\section{Referências}

Andrade, E. M.; Araújo, L. F. P.; Rosa, M. F.; Gomes, R. B.; Lobato, F. A. O., 2007. Seleção dos indicadores da qualidade das águas superficiais pelo emprego da análise multivariada. Engenharia Agrícola, v.27, n.03, 683-690.

Aquino, R. P. et al., 2016. Análise da vulnerabilidade natural e do risco de degradação no alto curso do rio Banabuiu-CE. Revista Brasileira de Geografia Física, v.09, n.02, 601-613.

Brasil. Ministério das Minas e Energia. Secretaria Geral., 1981. Projeto RADAMBRASIL. Levantamento de Recursos Naturais, v. 23, Folhas SB 24/25 Jaguaribe/Natal, Rio de Janeiro.

Caniani, D. et al., 2016. Habitat ecological integrity and environmental impact assessment ofanthropic activities: A GISbased fuzzy logic model for sites of highbiodiversity conservation interest. Ecological Indicators [On-line], v. 67, 238$249 . \quad$ Disponível em: www.elsevier.com/locate/ecolind. Acesso em: 22 nov. 2016.

CPRM - Serviço geológico do Brasil. Mapa geológico do Estado do Ceará., 2003. Escala 1:500.000, Ceará. CPRM.

Crepani, E.; Medeiros, J. S.; Azevedo, L. G.; Duarte, V.; Hernadez, P.; Florenzano, T.; Barbosa, C. C. F,1996. Curso de sensoriamento remoto aplicado ao zoneamento ecológico-econômico. INPE. São José dos Campos

Crepani, E.; Medeiros, J. S.; Azevedo, L. G.; Duarte, V.; Hernadez, P.; Florenzano, T.; Barbosa, C. C. F, 2001. Sensoriamento remoto e geoprocessamento aplicados ao zoneamento ecológico-econômico e ao ordenamento territorial. INPE. São José dos Campos

Fernandes, A., 1998. Fitogeografia brasileira. Multigraf, Fortaleza.

Fernandes, A., 2006. Fitogeografia brasileira: províncias florísticas, $3^{\mathrm{a}}$ ed. Realce editora e indústria gráfica, Fortaleza.

Gomes, A. G., 2005. Avaliação da vulnerabilidade à perda de solo em região semi-árida utilizando sensoriamento remoto e geoprocessamento - área piloto de Parnamirim 
(PE). Instituto Nacional de Pesquisas Espaciais, São José dos Campos.

Gomes, A. R.; Crepani, E.; Carvalho, V. C.; Medeiros, J. S., 2005. Aplicação da metodologia ZEE para a análise da vulnerabilidade à perda de solo em ambiente semi-árido. In: XII Simpósio Brasileiro de Sensoriamento Remoto. Anais XII Simpósio Brasileiro de Sensoriamento Remoto. Goiânia, Brasil.

$\mathrm{Hu}, \mathrm{X}$. et al., 2014. Integrated water resources management and water users' associations in the arid region of northwest China: A case study of farmers' perceptions. Journal of Environmental Management [On-line], v. 145, 162-169. Disponível em: www.elsevier.com/locate/jenvman. Acesso em: 22 nov. 2016.

Lopes, F. B. et al., 2011 Uso de geoprocessamento na estimativa da perda de solo em microbacia hidrográfica do semiárido brasileiro. Revista Agro@mbiente [On-line], v. 5, n. 2, 88-96. Disponível em: https://revista.ufrr.br/agroambiente/article/vie w/503/581. Acesso em: 23 nov. 2016.

Luers, A. L., 2005. The surface of vulnerability: An analytical framework for examining environmental change. Global Environmental Change [On-line], v.15, 214-223. Disponível em: www.elsevier.com/locate/gloenvcha. Acesso em: 22 nov. 2016.

Mota, L. H. S. O.; Valladares, G. S., 2011. Vulnerabilidade à degradação dos solos da Bacia do Acaraú, Ceará. Revista Ciência Agronômica, v. 42, n. 1, 39-50.
Panagos, P. et al., 2015. The new assessment of soil loss by water erosion in Europe. Environmental Science \& Policy, v.54, 438447.

Pinheiro, F. S. A., 2015. Vulnerabilidade a erosão e morfodinâmica na sub-bacia do rio Figueiredo, CE. Universidade Estadual do Ceará - UECE, Fortaleza.

Rodrigues, S. C.; Souza, N. C., 2013. Mapeamento da fragilidade ambiental no trecho de vazão reduzida do Rio Araguari (MG) com técnicas de geoprocessamento. GEOUSP - Espaço e Tempo, São Paulo, n. 35, 129-142.

Swami, M. V.; Mattos, A., 1975. Hidrologia aplicada. McGraw-Hill do Brasil, São Paulo.

Tiburan Jr., C.; Saizen, I.; Kobayashi, S., 2013 Geospatial-based vulnerability assessment of an urban watershed. In: The $3^{\text {rd }}$ International Conference on Sustainable Future for Human Security SUSTAIN 2012. Procedia Environmental Sciences, v. 12, 263-269. Disponível em: www.sciencedirect.com. Acesso em: 22 nov. 2016.

Tran, L.T.; O'neill, R.V.; Smith, E. R. A., 2012 watershed-based method for environmental vulnerability assessment with a case study of the Mid-Atlantic region. Environmental Impact Assessment Review, v. 34, 58-6. Disponível em: www.elsevier.com/locate/eiar. Acesso em: 22 nov. 2016.

Tricart, J., 1977. Ecodinâmica. IBGE, Rio de Janeiro. 